\title{
AUTOMATIC PANTRY SYSTEM IN RAILWAY USING ZIGBEE
}

\author{
Mr. D. G. Gahane \\ Associate professor \\ Department of Electronics and Telecommunication \\ Priyadarshini College of Engineering, Nagpur, MH, India
Siddhant Burde, Mitali Bawankule, Manasvi Khairkar, Prajakta Bijekar.
Student
Department of Electronics and Telecommunication
Priyadarshini College of Engineering, Nagpur, MH, India

\begin{abstract}
Indian railway (IR) is one of the world's best transporting system. It is mainly used for mass transportation. Also it is an affordable and effective all the way. 23 million passengers are travelling by the train per day and $\mathbf{7 . 2}$ billion passengers every year. The most important thing is that, attention has been paid time to time to the public comforts and their needs by introducing new things without increasing the fare since last few years. The aim is to build Automated Pantry Order System using ZIGBEE. A more advantageous system with it's advantages and disadvantages, over current food ordering system in IR which is totally manual system. The popularity of Indian railway and scope of our proposed system along with other ICT improvement is mentioned in the paper. Also the block schematic, hardware description and software description of Automated Pantry Order System using ZIGBEE is explained.
\end{abstract}

Index Terms-Arduino, Zigbee, IC 7805 ,LCD Display, Keypad

\section{INTRODUCTION}

We usually travel in the railways and sometime face the problems in ordering the food in the odd time. An Automatic Pantry Order System is basically a project which is designed to overcome this problem. We are providing zigbee based order placement section in each division.

Transmitter and Receiver sections are interfaced with zigbee module. The Order can be approved if and only if the traveller has the legal PNR number which is mentioned on the ticket.

\section{OBJECTIVE}

The aim is to build this project is to give the attention to the public comforts and their wish for introducing fresh things out. This is a most convenient ordering system than the present food ordering system in the railways which is totally hand operated system.

\section{LITERATURE SURVEY}

Debating about the Indian Railway's Pantry Order Systems, which is totally manual system. Suppose a traveller wants to order any snacks or meal during travelling they cannot get immediate access to seller. Unless and until a vendor comes to take order, due to this process a traveller cannot order at odd time.

After ordering the meal costumer have to wait for the bill payments. This drawback can be overcome by this project. It will try to provide the total automation technology. Due to this project the costumer can regimented at odd time and the problems can be solved. In India almost 65 to $75 \%$ people travel by the train for long journey and transporting industrial goods from one place to another place. Remaining people uses the other modes of transport such as Roadways, Seaways, Airways. The Conclusion of this project is that the railways are the most important source of the travelling used in India by the people. So it's most probable that our proposed to implement this project in the long journey trains for example, Duranto, superfast and Rajdhani Expresses, etc. as the no. of passengers are increasing gradually, our project can be more useful. If such reliable and feasible service is come into the existence then it will be more helpful for the passengers who travel the long Distance. 


\section{International Journal of Engineering Applied Sciences and Technology, 2019 \\ Vol. 4, Issue 1, ISSN No. 2455-2143, Pages 54-57 \\ Published Online May 2019 in IJEAST (http://www.ijeast.com)}

\section{PROPOSED SYSTEM BLOCK DIAGRAM}

\section{A. TRANSMITTER SECTION}

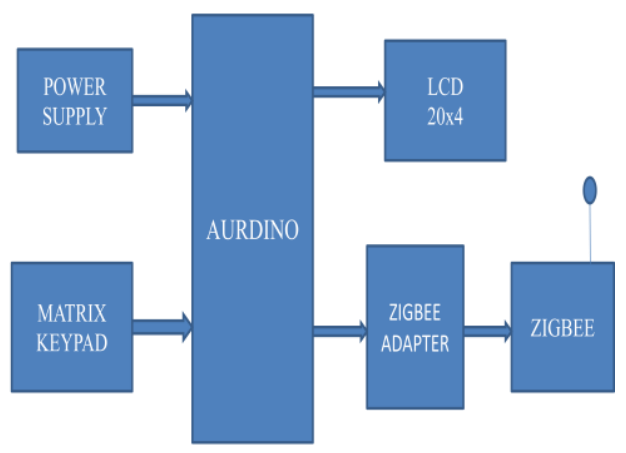

B. RECEIVER SECTION

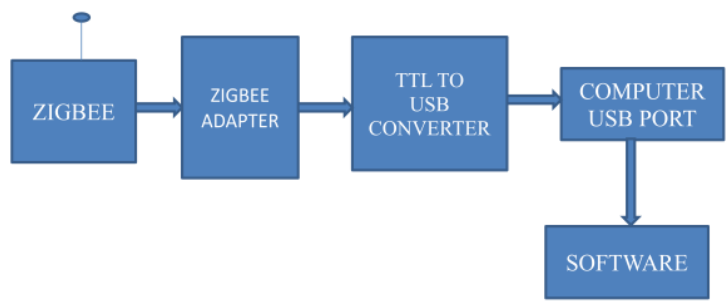

Figure 1: Block diagram of pantry system in Railways.

\section{WORKING OF DIFFERENT SECTIONS}

\section{A. Arduino Nano}

The Arduino Nano can be powered through the Mini-B USB connection, 6-20V unregulated external power supply (pin 30 ), or $5 \mathrm{~V}$ regulated external power supply (pin 27). The power source is automatically selected to the highest voltage source.

\section{B. Zigbee Module}

Zigbee is an open global standard for wireless technology designed to use low-power digital radio signals for personal area networks. ZigBee operates on the IEEE 802.15.4 specification and is used to create networks that require a low data transfer rate, energy efficiency and secure networking. The range of ZigBee is up to $1.6 \mathrm{~km}$

\section{Voltage Regulator IC 7805}

Voltage sources in a circuit may have fluctuations resulting in not providing fixed voltage outputs. A voltage regulator IC maintains the output voltage at a constant value.7805 is a voltage regulator integrated circuit. 7805 IC, a member of 78xx series of fixed linear voltage regulators used to maintain such fluctuations, is a popular voltage regulator integrated circuit (IC). The $\mathrm{xx}$ in $78 \mathrm{xx}$ indicates the output voltage it provides.

\section{ADVANTAGES}

- Rate of transmission and reception is fast.

- User friendly device, easy to access for children as well as senior citizens.

- Power required for operating the system is low.

\section{APPLICATION}

- It is use in pantry service in train.

- It can be used as E-menu in hotels or restaurants.

- It can be used as a E-notice board where user can type their queries get their answer.

\section{RESULT}

We have made the set of the system using microcontroller to perform different function by programming the microcontroller in embedded in $\mathrm{c}$ program. with the help of push to an switches order can be place and then with cc2500 RF module transmit it to the receiver and as soon as the operator see the order he send a confirmation massage to the sender with the bill of the food which is being displayed on LCD connected in transmitter side. this is how project work and we have operated the project and the work is successful. we have repeated the process and the result is shown in the analysis part below

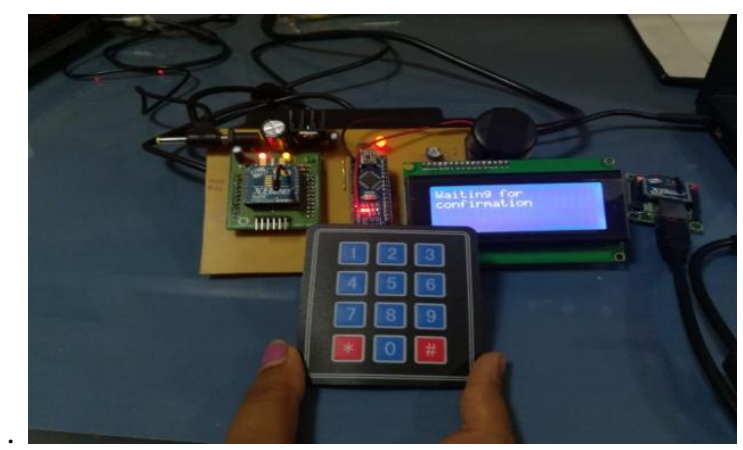




\section{REFERENCES}

\section{FUTURE SCOPE}

- In this project we used less food item in menu to reduce the complexity which can be increased.

- We can use the doctor facility in the train in case of emergency by displaying the emergency information in all bogies, police available.

- In this system, we can use two ATM payment facility but for this we need internet facility on the train.

- Touched screen system can be used on place of present system that we are using.

\section{CONCLUSION}

We have implemented this project as a food ordering system in train. As we are making the system to transmit data wirelessly, as it has fast transmission and also response is good. The overall procedure is placing the order is very easy and simple for the common people and it reduced the labor cost for delivery boys and the passengers also get the proper service in the train without having any trouble. This project is useful for those people who travel for whole night in train for non-stop long distance.
- Zeeshan M., Aaditya K., and Pooja G., (2013) "train operation management system on android operating system using Ad-hoe Network, UJERMCA, vol.2, Issue 3, march $2013+$

- Markus P. (2000) "higher vibration mode in railway track at their cutoff frequencies". Thesis, swiss federal institute of technology, 2000.

- Bimming T., Song H., Liu L., Sagar K., Sazia P., (2011) "towards enhanced key mannagment in multi phase Zigbee network architecture". Vol,35,pp.579-588,Dec.2011.

- $\quad$ www.indianrailway.gov.in

- Kamran S., (1995) "design of fast food restaurant system using statement tool".

- Thesis, university of Waterloo, Ontario, Canada, N2L, 3GI, Nov 1995.

- $\quad$ www.wekipedia.com

- Book related to wireless communications.

- Facilitating communication between pantry unit and bigie onboard high speed long route trains, IPASJ International journal of electrical Engineering(IIJEE) web site: http://www.ipasj.org//IIJEE/IIJEE.htm a published for research motivation......Email: editoriijee@ipasj.org 